\title{
REFLEXÕES SOBRE UM NOVO TIPO DE PROFESSOR UNIVERSITARIO É POSSÍVEL? ${ }^{1}$
}

\author{
Por Daniel Sotelo
}

\section{RESUMO}

A questão de uma questão de um professor universitário é possível. A situação de um novo tipo de professor universitário. Como uma nova universidade é necessária. Devemos ter uma nova forma de docência universitária.

\footnotetext{
${ }^{1}$ Autor: Dr. Daniel Sotelo, formado em filosofia e teologia, mestre e Doutor em Ciências da Religião. Pós doutorando em Educação.
} 
Existe uma necessidade profunda de um novo de tipo de professor universitário. Como também há uma necessidade de uma nova universidade. Necessita uma mudança nas formas de professorado e de instituição universitária. As situações sociais, políticas e econômicas promovem uma mudança radical para pior na formação do professor universitário, da universidade e dos próprios alunos. A sociedade deveria promover um contexto social melhor valorizando o sujeito, a participação da mesma nas decisões e nas transformações tecnológicas e nos meios de comunicação. Há uma pressão social exigindo um novo modelo de professor universitário que não esteja dominado pela tecnologia, mas que saiba unir a ciência com a investigação e a gestão.

Torna-se cada vez mais importante a forma dessa nova docência e da formação psicopedagógica para aprender a ensinar, educando os estudantes em valores e éticas, no domínio das emoções e em todos os aspectos sócioambientais. As novas alternativas sobre a formação do professor para que este aja de conformidade com o capitalismo, processos sociais e instrumentos de formação ultrapassados são cada vez mais divulgados pelo neocapitalismo. A exigência de especializações, cursos de formações para docentes universitários, uma reestruturação da própria universidade, dos funcionários desta universidade permite uma autorreflexão sobre os docentes em sala de aula.

\section{NOVO PROFESSORADO}

Tentamos imaginar um novo tipo de professor e uma nova universidade. Isto obriga a correr um risco, um esforço de imaginar os equívocos que são gerados pela vida, pela maneira de perceber o contexto social e um futuro imprevisível. Pensamos num exercício profético que tem lugar um futuro marcado pela mudança e pela incerteza. A dúvida está na questão da análise como pode/deve ser a universidade futura e assim como deve ser o docente universitário.

O enfoque principal e mais elementar nos leva a perguntar sobre a idéia radical e global: a universidade deve mudar radicalmente e converter-se numa 
universidade totalmente diferente. Ela deve mudar conforme as mudanças cada vez mais velozes que tem ocorrido neste século. A universidade deve deixar de lado a concepção antiquada de que procede e que tem se tornado ultrapassado, assumindo uma nova cultura na forma e conteúdo.

Outra análise consiste de que a sociedade penetrou na universidade e não vice versa. A sociedade duplicou nesses últimos anos o conhecimento acumulado pela humanidade. $O$ auge da tecnologia nos grandes meios de comunicação e informação, a formação contínua da ciência social, a critica do método cientifico tradicional, o conceito de ciências, as atitudes sociais novas, o debate do que se deve ensinar, a formação contínua dos indivíduos, o neoliberalismo veloz, os novos meios de formação, influíram grandemente na universidade. E deveria servir para que a mesma saísse da tutela, do estancamento e das rivalidades de grupos de pesquisa. A universidade não pode se auto renovar e que os que trabalham nela não devem dedicar-se apenas em decretos e leis, mas em decisões.

A universidade evoluiu neste século e fez isto sem romper as diretrizes que marcaram o seu nascimento: transmissão, seleção, consciência. A universidade não é aquela instituição que no século passado ao passar do centro universitário o estudante tinha um verdadeiro privilégio, este pertencia a uma elite. Precisamos tem em conta que a educação universitária era um processo ligado a uma categoria social e não um meio para conseguir essa categoria social. Esta evolução e extensão de outras camadas sociais, deve permear a universidade do futuro para que haja uma concepção de instituição que deve educar na vida e para a vida.

A universidade deve educar realmente na vida e para a vida e superar estes enfoques tecnológicos, funcionalistas e burocratizantes. A universidade dentro e fora, nas suas relações e práticas deve ter um caráter mais relacional, cultural, contextual e comunitário. O seu âmbito deve ter a importância da interação entre todas as pessoas vinculadas, seja no trabalho nela como condição de usuário, de agente social ou como apenas membros de uma comunidade.

A interação dela com a comunidade devem refletir o dinamismo social e cultural da instituição que é a comunidade e que está a serviço da mesma. A universidade deve ser o lugar na qual se aprende uma profissão, um ofício, 
uma vocação, não importa qual seja para ter a manifestação de vida em todas as suas relações e disposições com uma comunidade que seja de modo institucional de conhecer, investigar e ensinar o mundo e suas manifestações.

O futuro do ensino e do aprendizado deve passar pela questão de como ser cidadão e como isto se concretiza: democrática, social, solidária, igualitária, intercultural e meio ambiental. Os lugares que isso deve ocorrer está em contradição com pobreza endêmica ou a neo miséria, emergida numa povoação de analfabetos cívicos. A universidade precisa de outros modos culturais e sociais que ajudem no processo de formar o cidadão. Isso está dentro da formação universitária, muito mais do que no ensinar/transmitir a uma minoria homogênea, numa época em que o conhecimento e a gestão estão em poder de poucas mãos, que monopolizam o saber.

\section{O CONTEXTO SOCIAL}

A formação dos seres humanos cada vez mais é complexa. A profissão de docente universitário também o é. Nessa complexidade vemos a mudança radical e veloz das estruturas científicas, sociais e educativas que dão apoio e sentido à instituição do sistema educativo.

A universidade e o trabalho nela serão marcado por um contexto que se desenvolverá no futuro ou presente:

- A mudança veloz nas formas da comunidade social, no conhecimento científico e nos produtos do pensamento, cultura e arte;

- A evolução rápida da sociedade através das estruturas materiais, institucionais, organizacionais, convivência, modelos de família, de produção e distribuição, refletem na mudança inevitável das formas de pensar, sentir e atuar das novas gerações;

- Os contextos sociais condicionam a educação e fazem refletir uma serie de forças em conflito. As mudanças rápidas pelos meios de comunicação e tecnológicos forma acompanhados por transformações profundas na vida das instituições e organizações, colocando em crise a mera transmissão do conhecimento e das instituições; 
- Fazendo uma análise da formação dos docentes e da comunidade, dos meios que esta possui, estabelecemos novos modelos de relações e participações na prática da educação.

Não podemos esquecer que na atualidade o sistema social educativo, a desregularização, as idéias e práticas neoliberais, conservadoras e as tendências de gerenciamento baseadas em critérios de rendimento e mercado. A organização de uma sociedade democrática deveria permitir criar na universidade, intelectuais coletivos, espaços de resistência e liberdade intelectuais suficientes para intervir com crítica e autonomia pessoal e profissional nestas instituições. O processo de mudança precisa estar alerta para impedir que se reconceitualize os sistemas econômicos e regulação (oposto da desregularização do estado) do mercado para colocar na universidade elementos que são processos de autonomia vigiada, de ingerenciamento, de mais competência entre as pessoas e de grandes valores.

Nos últimos tempos vemos a questão de um conhecimento de noções e imutáveis das ciências que se abre para certas concepções em que as mudanças e a incerteza têm um papel preponderante. Foi-se incorporando, num debate sobre as práticas universitárias, os aspectos éticos, relacionamentos, colegiado, atitudes, emoções reflexões. Tudo isso foi necessário para conseguir uma melhor formação cientifica e democrática dos futuros cidadãos e cidadãs. Começou assim a valorizar a importância do sujeito (na modernidade a importância era a razão, objeto e na pós-modernidade a relatividade e o sujeito). A participação do professor, a relevância que ele adquire com a bagagem sociocultural - a comunicação, o trabalho em grupo, o debate democrático, a aprendizagem dialógica, os processos são mais que produtos, a elaboração conjunta de projetos, a tomada de decisões democráticas, a análise de situações está na concretização do futuro.

No futuro precisamos de uma universidade melhorada e uma nova forma de educar em estruturas organizadas universitárias diferentes e isso requer romper com a burocracia institucional. Para romper esta burocracia precisa-se reconceitualizar a universidade e a docência universitária. Precisa de uma forma de novas competências profissionais por parte do professorado. Esta nova forma precisa de uma universidade, uma formação universitária e um docente profissional bem diferente dos atuais. 


\section{A FORMAÇÃO DO DOCENTE UNIVERSITARIO}

A formação está vinculada ao desenvolvimento profissional, deve ser um processo continuo que começa com a escolha de uma disciplina concreta (formação inicial num oficio ou profissão) e domínio (conhecimentos, habilidades, competências) que vai se aperfeiçoando devagar (formação contínua e permanente).

A formação inicial é uma primeira fase. O objetivo é ter profissionalidade, integração das competências para uma socialização profissional. $O$ outro objetivo que é a segunda fase deve encontrar soluções em situações problemas que se apresentam no cumprimento das funções profissionais.

A questão insolúvel da formação dos docentes universitários, tanto numa como na outra fase, a socialização ou formação permanente, deve obedecer duvidas e indeterminações sobre qual deve consistir realmente a sua socialização profissional ou seu trabalho profissional especifico como docente.

O professor universitário se forma basicamente no conteúdo cientifico da matéria que ensina e que investiga. Isto é quase vago ou nulo o interesse do docente universitário sobre a formação que precisa para transmitir e compartilhar esse conhecimento com os estudantes.

Pode comprovar-se na experiência a dificuldade de superar o velho e ultrapassado suposto que o bom professor é aquele que domina a ciência, já que o conhecimento o capacita por si mesmo para ensiná-la e que o melhor docente é o que mostra aptidões e boa vontade. Como ultrapassar esse fantasma da docência universitária? O conhecimento vulgar pedagógico, que foi interiorizado durante muitos anos de aulas universitárias como estudantes, antes de ser docente. Isto impõe um modelo de transmissão semelhante, como aquele currículo que nada vale e que se aprende a ensinar mediante as estruturas e relações que tiveram e se tem, na formação especifica, na reflexão e no contraste das idéias.

Atualmente o professor universitário começa a ter uma consciência de que o modelo não é suficiente (nefasto), sobre o qual a experiência mostra o predomínio de uma transmissão normativa ou de noções, e que não tem prérequisitos de uma transmissão mais descritiva, mais regulativa. 
Há uma nova forma de transmitir e compartilhar o conhecimento científico, e que a formação inicial e permanente do professor universitário é imprescindível e também necessária numa universidade que olha o futuro como uma nova forma de ensinar. A nova universidade deve superar os velhos esquemas e antigas ideologias acadêmicas sobre a docência predominantes e obsoletas.

É difícil colocar-se na formação docente universitária se:

- Qual é a função importante da profissão universitária: a investigação, a docência, a gestão ou todas elas?

O debate sobre a formação do docente universitário deve ser sobre as estruturas pedagógicas necessárias, sobre a metodologia, os foros didáticos ou debater sobre a profissão docente de forma completa. Essa discussão ainda está por se fazer, é necessária a tradição de pensamento e reflexão.

A sociedade pede que a universidade deva mudar totalmente conforme são as mudanças que tem se produzido nos últimos anos (os rápidos avanços científicos e técnicos e a mudança do conhecimento, as novas atitudes sociais, as novas profissões, e o uso das tecnologias). Essa mudança ocorre cada vez mais na universidade como na investigação cientifica. A docência pertence a outro mundo já que existem dois mundos na universidade: o mundo do discurso acadêmico, a teoria cientifica e a investigação, o mundo da docência e a sua prática. Podemos agrupar e equilibrar, estabelecer formas de convivência entre esses problemas? Começamos a ver caminhos cruzados nos dois mundos, com duas culturas. Na docência universitária algo vai mudando. Removeram-se certos supostos que antigamente não se mudaram.

A ignorância de uma parte do professor universitário, sobre o como ensinar o que se sabe, o desinteresse e a desconfiança da pedagogia (a pedagogia como realidade formativa mudou os enfoques conceituais de tendências ruins nas técnicas pedagógicas), criou-se uma tímida mudança e fez surgir novas propostas.

O discurso universitário, a competitividade, os critérios de rendimento e mercado e alguns fatores sociais (baixa natalidade, mudança de sistema educativo, novas mudanças sociais) geraram uma preocupação institucional mais que o próprio interesse do coletivo docente universitário. 


\section{CONCLUSÃO}

A formação da docência universitária, inicial ou permanente tem uma parte relacionada com a profissão universitária e os processos de institucionalização. Não devemos cair em certos erros:

- a realidade social, acadêmica, cientifica mostrou que a profissão docente universitária é complexa e não é uniforme. As mudanças das estruturas científicas, sociais e educativas (penetram as disciplinas e atitudes dos professores e estudantes) incrementando essa complexidade. Faze uma formação uniforme de todo professorado sem ter em conta essa complexidade é um grande erro.

A formação na docência universitária é contextual. Não pode explicar os fenômenos educativos generalizando as ações nesses contextos. A realidade universitária (estudantes, culturas acadêmicas, contextos, ensinos) mostra que a interpretação dos fenômenos docentes deve ser contextualizada em cada realidade. Não se mudará a docência universitária se o objetivo da formação é só mudar as pessoas e que mediante a mudança pessoal, a formação personalista se mudará a prática docente.

- a formação deve penetrar as pessoas e os contextos (processo de comunicação, estruturas, políticas, relações de poder, tomadas de decisão, autonomia) para gerar inovações na instituição.

- a formação do docente universitário deve estar prenha de valores, de formas a interpretar a realidade. Esta profissão deve dedicar-se a transmitir e a dividir conhecimentos e atitudes. A formação é mais baseada em atitudes, em processos, que em metodologias. Será maior beneficio para a reflexão, para a mudança e inovação na docência universitária. 
BIBLIOGRAFIA

CHAMLIAN, Helena C. Docência na universidade: professores inovadores na USP. Cadernos de pesquisa n. 118, p 41-64. Março. 2003.

CUNHA, Maria Isabel. Docência na universidade, cultura e avaliação institucional: saberes silenciados. Revista Brasileira Educação, Volume 11 número, 32 Rio de Janeiro maio/agosto, 2006.

OLIVEIRA, Valeska F. Professor universitário. In: Morosini, Maria da C. (org) Enciclopédia de pedagogia universitária. Porto Alegre. FAPERGS/RIES, 2003. p. 252-261. 
